Check for updates

Cite this: RSC Adv., 2017, 7, 45607

\title{
Microwave-assisted seed preparation for producing easily phase-transformed anatase to rutile $\uparrow$
}

\author{
Siyang Tang, (D)* Yaowen Zhang, Shaojun Yuan, D Hairong Yue, Changjun Liu, \\ Chun Li and Bin Liang
}

Titanium dioxide, as one of the most important optical materials, is usually manufactured by the hydrolysis of titanyl salts, in which the seeds are a key to affect product properties. In the sulfate process, hydrolysis normally leads to anatase which is then converted to rutile in a high-temperature calcination with the help of a crystal transforming agent. In this work, the initial seeds were prepared through microwave heating and then the seeds were introduced to the hydrolysis of dilute titanyl sulfate solution. The results showed that the hydrolysis product had a narrower particle size distribution compared with traditional processes, and it was much more easily converted to rutile product under low-temperature calcination in the absence of a crystal transforming agent. The microwave effects on the seed preparation conditions were evaluated, and the kinetic behavior of the seeds in hydrolysis was also studied.

Received 4th July 2017

Accepted 10th September 2017

DOI: $10.1039 / \mathrm{c} 7 \mathrm{ra0} 3385 \mathrm{~b}$

rsc.li/rsc-advances

a high-temperature calcination process. Rutile is a more stable

\section{Introduction}

Titanium dioxide $\left(\mathrm{TiO}_{2}\right)$ is an inorganic chemical well known for its good optical performance, inertness and environmentally friendly chemical properties, and it is widely used in pigments, papermaking and ceramics. ${ }^{1-3}$ Of the two main kinds of crystal $\mathrm{TiO}_{2}$, rutile has better pigment properties than anatase.

In past decades, two titanium dioxide manufacturing technologies have been developed based on sulfate and chloride, respectively. The chloride process produces rutile product directly by a high-temperature rapid gaseous reaction, but this process needs high-quality titanium minerals like natural rutile and high Ti content slags as its feedstock materials. ${ }^{3-6}$ The other manufacturing method, the sulfate process, however, can be directly fed with low Ti content materials like ilmenite, which is rather cheap. $\mathrm{TiO}_{2}$ product manufactured by the sulfate route still represents about $50 \%$ of global $\mathrm{TiO}_{2}$ production.

In the sulfate process, $\mathrm{TiO}_{2}$ is prepared by the hydrolysis and calcination of titanyl sulfate solution., ${ }^{3,6-20}$ Metatitanic acid as the direct hydrolysis product is washed and then calcined to obtain $\mathrm{TiO}_{2}$. The properties of the hydrolysis particles decide the quality of the final $\mathrm{TiO}_{2}$ product, and it is greatly dependent on the control of the hydrolysis conditions. Because the titanium salt is easily hydrolysable, it is difficult to control the morphology, particle size and particle size distribution of $\mathrm{TiO}_{2}$.

Normally, the metatitanic acid obtained from the hydrolysis of titanyl sulfate solution would produce anatase-form $\mathrm{TiO}_{2}$ in

Multiphase Mass Transfer and Reaction Engineering Laboratory, Sichuan University, Chengdu 610065, China. E-mail: siyangtang@scu.edu.cn; Tel: +86-028-85997677

$\dagger$ Electronic supplementary information (ESI) available. See DOI: $10.1039 / \mathrm{c} 7 \mathrm{ra} 07385 \mathrm{~b}$ crystal form of $\mathrm{TiO}_{2}$ and it has better optical properties for pigments than anatase. In the commercial sulfate process, rutile-form $\mathrm{TiO}_{2}$ product is obtained by crystal transformation of anatase in a high-temperature calcination $\left(>1000{ }^{\circ} \mathrm{C}\right)$ in the absence of a crystal transforming agent. ${ }^{3,21,25}$ And some studies (including study of metatitanic acid conducted under ultrasound field) also show that a calcination under $900^{\circ} \mathrm{C}$ over $2 \mathrm{~h}$ is necessary to ensure full crystal transformation., ${ }^{3,22-26}$

Hydrolysis is the most important operation in the sulfate process. ${ }^{3,15,27,28}$ A narrow particle size distribution (around 1-2 $\mu \mathrm{m}$ ) of the hydrolysis particles is the key factor to obtain good optical properties of the final product. Early hydrolysis operations were conducted by self-generating nuclei crystallization, in which particle size control is very difficult. The initial nucleus seeds are formed by dropping the titanyl sulfate solution into hot water. Because the crystal growth is non-reversible, the initial nuclei decide the final particle size distribution and the particle activities. The self-nucleation process is an unstable process, which is greatly influenced by parameter control.

By adding nucleus seeds, the hydrolysis process can be well controlled. The nucleus seeds are usually called external crystal seeds. Ideal nucleus seeds are in the range of 2-3 nm with a narrow size distribution, and their dosage in hydrolysis is about $1-2.5 \% .^{3,15,28,29}$ The seeds are generally prepared by neutralizing titanyl sulfate solution with hot sodium hydroxide solution, in which the seed properties are dependent on the reaction conditions, such as temperature, feed ratio and addition rate.

However, the present hydrolysis process cannot afford high crystal-transfer active metatitanic acid. And the titanyl sulfate solution is required to be concentrated from $120 \mathrm{~g} \mathrm{~L}^{-1}$ to $180-$ 
$220 \mathrm{~g} \mathrm{~L}^{-1}$ in order to match the needs of hydrolysis. This results in the consumption of much energy in evaporation.

With the development of microwave technology, ${ }^{30-34}$ microwave-assisted technology is successfully used to synthesize nanometer titanium dioxide materials. ${ }^{35-40}$ In this work, a novel hydrolysis method was developed, in which microwaveassisted technology was applied in the preparation of nucleus seeds. The technology can produce uniform and active seeds, and the seeds can induce the hydrolysis of dilute titanyl sulfate solution and result in uniform precipitate particles. The hydrolysis particles are highly active in the following calcination operation and are easily converted to rutile $\mathrm{TiO}_{2}$ at a lower temperature in the absence of a rutile crystal transforming agent.

\section{Experimental}

The titanyl sulfate solution used for hydrolysis was prepared by using titanyl sulfate powder (Guangfu Chemical Research Institute, Tianjing, CP) and ferrous sulfate (Kermer, Tianjing, AR) to form a solution with a concentration of $160 \mathrm{~g} \mathrm{~L}^{-1}$ of $\mathrm{TiO}_{2}$ and $\mathrm{a} \mathrm{Fe} / \mathrm{TiO}_{2}$ mass ratio of 0.3 . And the sulfuric acid mass was 1.9 times of titanium dioxide mass.

The titanyl sulfate solution for seed preparation was prepared from the same titanyl sulfate source in absence of ferrous sulfate. The titanyl sulfate solution with a given concentration was heated in a microwave oven (Panasonic NNGF352M) for several seconds to obtain a seed sol. The solution was called the seed titanyl solution (STS). The stability of the seed sol was measured by the dilution method, in which $10 \mathrm{~mL}$ seed sol was diluted by adding water until the sol turned turbid. The stability of the seed sol is defined as the ratio of the volume of added water to the volume of seed sol:

$$
S=V_{1} / V_{2}
$$

where $V_{1}$ is the volume of water added and $V_{2}$ is the volume of seed sol.

Hydrolysis was conducted inside a $100 \mathrm{~mL}$ three necked flask with agitation under atmospheric pressure. In each batch, $50 \mathrm{~mL}$ of titanyl sulfate solution (the solution was called the hydrolysis titanyl solution (HTS)) was heated to $90-96{ }^{\circ} \mathrm{C}$ and then about $2 \%$ (mass ratio referring to titanium dioxide mass) seeds were inoculated. Keeping agitated at the temperature for $10 \mathrm{~min}$, the reactants were heated to boiling point (namely the first boiling point) and heating maintained for several minutes until the solution turned gray. After stopping heating and stirring, the slurry was aged for 30 minutes. And then, agitating again and heating to boiling point (namely the second boiling point) again, ${ }^{20}$ the slurry was hydrolyzed for another 3.5 hours. At last, the slurry was filtered and washed with $10 \%$ sulfuric acid solution and distilled water. The hydrolysis metatitanic acid, the filtration cake, was calcined at $850{ }^{\circ} \mathrm{C}$ in a muffle furnace for 30 minutes, and then cooled to room temperature.

The hydrolysis ratio was calculated as follows:

$$
Y=\left(1-m_{1} / m_{2}\right) \times 100 \%+0.5
$$

where $m_{1}$ : titanium dioxide concentration in slurry; $\mathrm{g} \mathrm{L}^{-1}, m_{2}$ : titanium dioxide concentration in the filtrate; $\mathrm{g} \mathrm{L}^{-1}, 0.5$ : the corresponding number. ${ }^{\mathbf{4 1}}$

The metatitanic acid particle size distribution was characterized by a particle size analyzer instrument (Runzhi Rise2002). And the particle size of the seeds was characterized by a Marvin nano-size analyzer instrument.

The XRD characterizations were carried out with a DX-2700 $\mathrm{X}$-ray diffractometer. The voltage and anode current were $40 \mathrm{kV}$ and $30 \mathrm{~mA}$, and $\mathrm{Cu} \mathrm{K} \alpha=1.5406 \mathrm{~nm}$ and continuous scanning mode with 0.03 interval and $0.05 \mathrm{~s}$ set time were used to collect XRD patterns.

Scanning electron microscopy (SEM) studies were carried out with a JEOL $7610 \mathrm{~F}$ electron microscope to examine the morphology of hydrolysis products and calcination products.

\section{Results and discussion}

In commercial hydrolysis operation, nucleus seeds are often used to initiate hydrolysis in the sulfate $\mathrm{TiO}_{2}$ process. It not only leads to a high hydrolysis ratio, but also ensures a narrow size distribution of products. ${ }^{3,27}$ In this work, the influence of microwave-assisted seed preparation on hydrolysis behaviors is discussed in detail. The products so obtained were analyzed and the following calcination was optimized. The seed properties significantly affect the crystal transformation of the product from anatase to rutile.

Parameter tests, including the microwave heating parameters and hydrolysis parameters, were conducted and the results are discussed in the following.

\subsection{Effects of microwave conditions on hydrolysis}

3.1.1 The hydrolysis behaviors. Microwave heating rate greatly influences the hydrolysis and crystallization of the titanyl solution. In the preparation process, the heating rate depends on the microwave power, which decides the seed behaviors. The microwave heating power was investigated in the range from $200 \mathrm{~W}$ to $800 \mathrm{~W}$, and microwave heating time varied from $30 \mathrm{~s}$ to $100 \mathrm{~s}$, respectively. In all seed preparations, referring to the solution component in industrial processes, the $\mathrm{Fe} / \mathrm{TiO}_{2}$ (mass ratio) and $\mathrm{H}_{2} \mathrm{SO}_{4} / \mathrm{TiO}_{2}$ (mass ratio) of the initial titanyl solution were maintained at 0.3 and 1.9 , respectively.

The results showed that microwave heating parameters significantly affected the seed stability and the hydrolysis ratio. In the range of 200 to $800 \mathrm{~W}$, the hydrolysis ratio increased with heating power and the stabilities of the seeds decreased (Table 1, no. 1-4). This means that high heating power during $60 \mathrm{~s}$ of given time resulted in a high activity of seeds. On the other hand, decreasing heating time also resulted in a hydrolysis ratio decrease and stability increase. However, $70 \mathrm{~s}$ of heating time led to a decrease of hydrolysis ratio. When the energy was suitable for seed formation, the seeds were mainly titanic acid. When more energy was involved in the seed preparation process, it would lead to oversaturated seeds, in which metatitanic acid seeds formed. Then the seeds would become grey, and active seed numbers decreased. ${ }^{14,16,42}$ To clarify the 
Table 1 Hydrolysis ratio under different operating conditions ${ }^{a}$

\begin{tabular}{|c|c|c|c|c|c|}
\hline No. & STS concentration $\left(\mathrm{g} \mathrm{L}^{-1}\right)$ & Heating power (W) & Heating time (s) & Seed stability & Hydrolysis ratio (\%) \\
\hline 1 & 30 & 800 & 60 & 10 & 95.4 \\
\hline 2 & 30 & 600 & 60 & 15 & 91.8 \\
\hline 4 & 30 & 200 & 60 & $>20$ & 71.4 \\
\hline 5 & 30 & 800 & 70 & $*$ & 72.0 \\
\hline 6 & 30 & 800 & 50 & 15 & 86.0 \\
\hline 9 & 35 & 800 & 70 & 10 & 94.7 \\
\hline 10 & 40 & 800 & 80 & 10 & 93.9 \\
\hline 11 & 45 & 800 & 90 & 10 & 91.9 \\
\hline 12 & 50 & 800 & 100 & 10 & 90.6 \\
\hline
\end{tabular}

${ }^{a}$ All hydrolysis tests were carried out as follows: $\mathrm{HTS}$ concentration was $160 \mathrm{~g} \mathrm{~L}{ }^{-1}$; Fe/ $/ \mathrm{TiO}_{2}$ mass ratio was $0.3, \mathrm{H}_{2} \mathrm{SO}_{4} / \mathrm{TiO}_{2}$ mass ratio was 1.9 . The seed addition was $2 \%$; temperature was $104{ }^{\circ} \mathrm{C}$; hydrolysis time (after the second boil point) was $3.5 \mathrm{~h}$. *The seeds turned grey, meaning precipitation could be observed.

relationship between the STS concentration and the microwave energy injected, experiments (as shown in Table 1, No. 1 and 9-12) were carried out. With an increase of the STS concentration, more microwave heating energy is required to ensure seed stability, but the hydrolysis ratio decreased slightly. The hydrolysis particles were almost the same, as shown in Fig. S1 and Table S1.†

To further evaluate the effects of the microwaves on the hydrolysis kinetic behaviors, the hydrolysis time with different microwave heating times of seed preparation were investigated as shown in Fig. 1. The hydrolysis time observed was up to $5 \mathrm{~h}$, while the microwave heating times of seeds preparation were $30 \mathrm{~s}, 40 \mathrm{~s}, 50 \mathrm{~s}$ and $60 \mathrm{~s}$. The heating power was $800 \mathrm{~W}$, and all the other conditions were the same as shown in Table 1.

As shown in Fig. 1, all the final hydrolysis ratios in 5 hours reached $90 \%$. But the hydrolysis reaction rates are different when using different seeds; they increased with the increasing

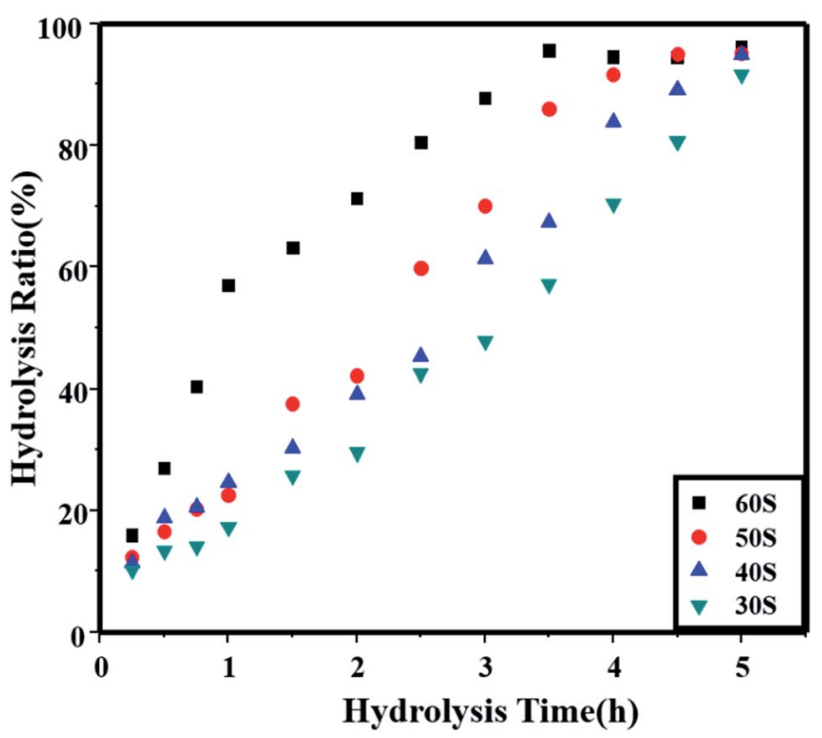

Fig. 1 Hydrolysis ratios for different microwave heating times. of heating time in seed preparation. When heating for $60 \mathrm{~s}$ in seed preparation, the seed stability was 10 and the following hydrolysis process finished in $3.5 \mathrm{~h}$. And for $50 \mathrm{~s}$ and $40 \mathrm{~s}$, the seed stabilities were 15 and $>20$, and the complete hydrolysis times were $4.5 \mathrm{~h}$ and $5 \mathrm{~h}$, respectively.

To understand the kinetic behaviors of the hydrolysis with microwave-assisted seeds, the hydrolysis results (as shown in Fig. 1, before hydrolysis equilibrium) were fitted with kinetic equations, ${ }^{\mathbf{4 3 - 4 7}}$ from which the hydrolysis process turned out to be a secondary autocatalytic reaction, these results being shown in Fig. 2 and Table 2, where the hydrolysis rate constants decreased with the microwave heating time decreasing.

3.1.2 The hydrolysis particles. The hydrolysis particle size distributions influence the $\mathrm{TiO}_{2}$ product size distributions and the pigment properties. Sizes were measured by a particle size analyzer instrument. The results were obtained and then fitted with a lognormal distribution. The particle size distribution

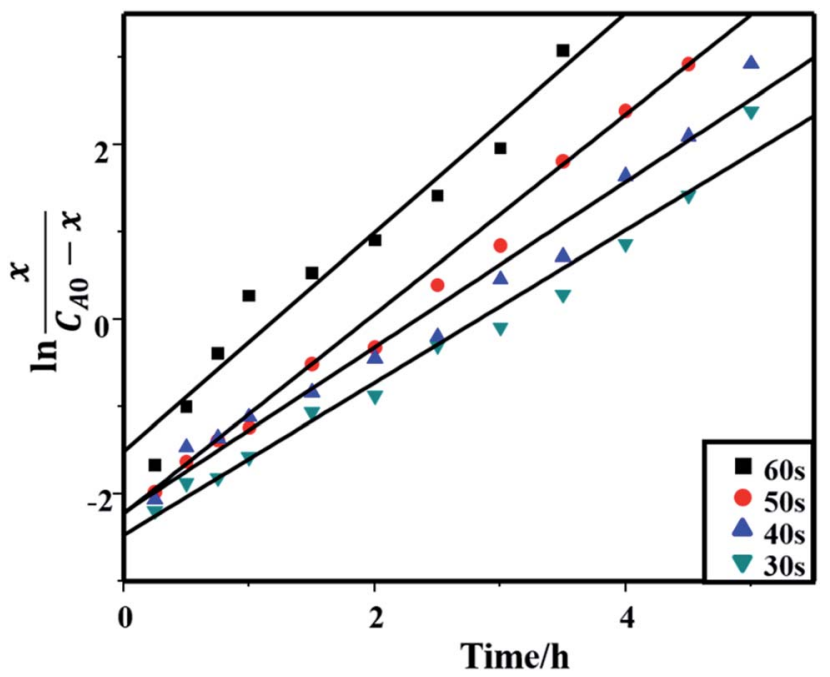

Fig. 2 The hydrolysis kinetic results of microwave seeds under different microwave heating times. 
Table 2 The hydrolysis rate constants for different seed microwave heating times ${ }^{a}$

\begin{tabular}{lll}
\hline $\begin{array}{l}\text { Seed microwave heating } \\
\text { time }(\mathrm{s})\end{array}$ & $\begin{array}{l}\text { Rate constant } \\
\left(\mathrm{L} \mathrm{mol}^{-1} \mathrm{~h}^{-1}\right)\end{array}$ & $\begin{array}{l}\text { Correlation coefficient } \\
\left(R^{2}\right)\end{array}$ \\
\hline 60 & 1.256 & 0.95 \\
50 & 1.143 & 0.99 \\
40 & 0.947 & 0.98 \\
30 & 0.872 & 0.98
\end{tabular}

${ }^{a}$ The HTS concentration was $160 \mathrm{~g} \mathrm{~L}^{-1}$, the STS concentration was $30 \mathrm{~g} \mathrm{~L}^{-1}$, the microwave heating power was $800 \mathrm{~W}$, the $\mathrm{Fe} / \mathrm{TiO}_{2}$ ratio was 0.3 and the $\mathrm{H}_{2} \mathrm{SO}_{4} / \mathrm{TiO}_{2}$ ratio was 1.9. The hydrolysis temperature was $104{ }^{\circ} \mathrm{C}$.

results of the hydrolysis particles under different microwave conditions are shown in Fig. 3 and Table 3.

Microwave heating rate greatly affects the properties of seeds and the following hydrolysis activities. Fig. 3 shows that the hydrolysis particle size distribution widens gradually with decreasing heating power, according to the results in Tables 1 and 3. The hydrolysis ratio increased from $71.4 \%$ to $95.4 \%$; however, the mean diameter slightly decreased from $1.935 \mu \mathrm{m}$ to $1.887 \mu \mathrm{m}$ and the variance of the particle size distribution decreased from 0.260 to 0.231 . And the same phenomenon could be found with the microwave heating time decreasing as shown in Fig. S2. $\dagger$ This means that the hydrolysis particles produced with the seeds of lower microwave intensity are less uniform than the particles of a higher microwave intensity. This suggested that the seed apparent activity would increase with increasing microwave intensity, and this would be the key factor for both hydrolysis rate increasing and a narrow hydrolysis particle size distribution.

Microwaves usually provide an integral temperature field in chemical synthesis. And in this work they were used to heat the seeds rapidly and integrally, which would lead to uniform seeds

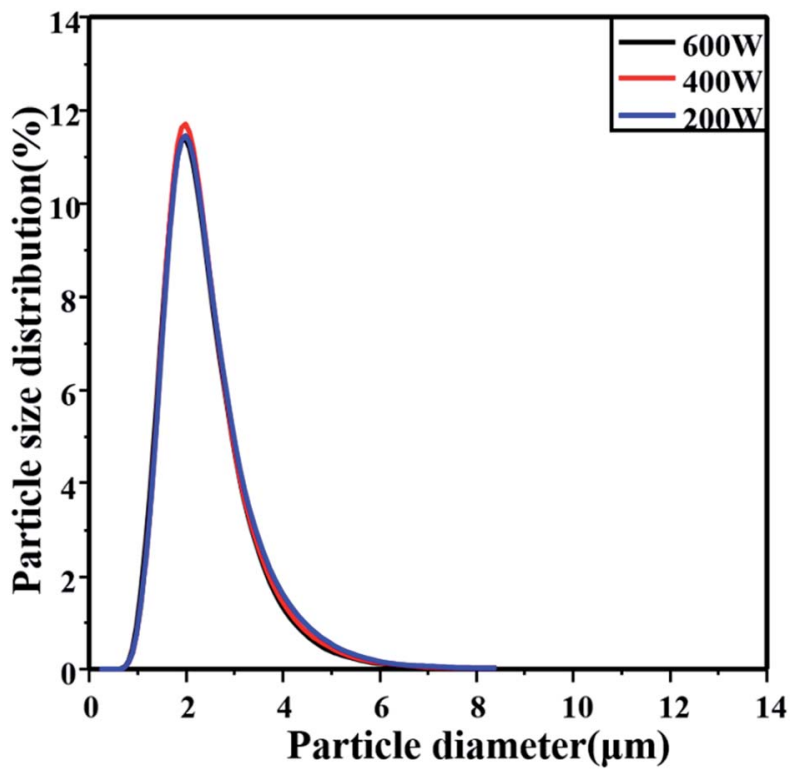

Fig. 3 The particle size distributions of metatitanic acid with different microwave heating powers.
Table 3 The variance for different particle size distributions ${ }^{a}$

\begin{tabular}{llll}
\hline & $\begin{array}{l}\text { Heating power } \\
(\mathrm{W})\end{array}$ & $\begin{array}{l}\text { Mean diameter } \\
(\mu \mathrm{m})\end{array}$ & Variance \\
\hline 1 & 800 & 1.887 & 0.231 \\
2 & 600 & 1.899 & 0.254 \\
3 & 400 & 1.921 & 0.248 \\
4 & 200 & 1.935 & 0.260
\end{tabular}

${ }^{a}$ The metatitanic acid particle size distribution was determined when the HTS concentration was $160 \mathrm{~g} \mathrm{~L}^{-1}$, the STS concentration was $30 \mathrm{~g} \mathrm{~L}^{-1}$, the microwave heating time was $60 \mathrm{~s}$, the $\mathrm{Fe} / \mathrm{TiO}_{2}$ ratio was 0.3 and the $\mathrm{H}_{2} \mathrm{SO}_{4} / \mathrm{TiO}_{2}$ ratio was 1.9.

for hydrolysis (particle size of seeds shown in Table S2†). Since the microwave-assisted methods always prepare uniform products, the activity of each seed could be considered even. Combining with the hydrolysis particle distribution results (as shown in Table 1 and Fig. S2 $\uparrow$ ), it suggests that the number of seeds formed under microwave conditions would decrease with a decrease of the microwave energy injected. The microwave heating effect on the seed preparation was proposed and it was compared with the traditional self-generating nuclei process (as shown in Fig. 4). With a lower number of seeds in the initial hydrolysis solutions, the apparent hydrolysis activity decreased and uncontrolled self-generating nuclei would easily form, which leads to a wider hydrolysis particle distribution. And as a result, the particle size distribution became wider, and the particle size increased slightly.

The final particle size was basically similar at the hydrolysis time observed, indicating that the microwave heating seems not to be the major factor affecting the original seed activity and the particle size (as shown in Table 3 and Fig. 3). But it affects the seed apparent activity formed in the seed preparation. It suggests that the seed number would be quite different with the microwave energy injected. As we discussed above, the microwave energy injected affects the seed stability, which would lead to different hydrolysis rates and different hydrolysis ratio of metatitanic acid. In an appropriate microwave energy range, the greater the microwave energy injected in the seed preparation, the more effective seeds would form. As a consequence, the seeds would be less stable but with a higher apparent activity, which could be represented as the hydrolysis rate. And the hydrolysis ratio would increase with the particle size and particle size distribution of metatitanic acid widens with the hydrolysis time increasing.

\subsection{Effects of hydrolysis conditions}

Hydrolysis conditions were optimized and the results are shown in Table $4 . \mathrm{Fe} / \mathrm{TiO}_{2}$ and $\mathrm{H}_{2} \mathrm{SO}_{4} / \mathrm{TiO}_{2}$ ratios varied in the range of $0-0.4$ and 1.9-2.5, and all these conditions are close to those of commercial processes. The amount of seeds added was changed in the range from 0.5 to $2.5 \mathrm{wt} \%$.

The hydrolysis ratio varied with $\mathrm{H}_{2} \mathrm{SO}_{4} / \mathrm{TiO}_{2}$ markedly, while the $\mathrm{Fe} / \mathrm{TiO}_{2}$ mass ratio did not much influence the hydrolysis ratio. With the $\mathrm{Fe} / \mathrm{TiO}_{2}$ mass ratio increasing, the hydrolysis increased slightly after a slight decrease. And all the hydrolysis 


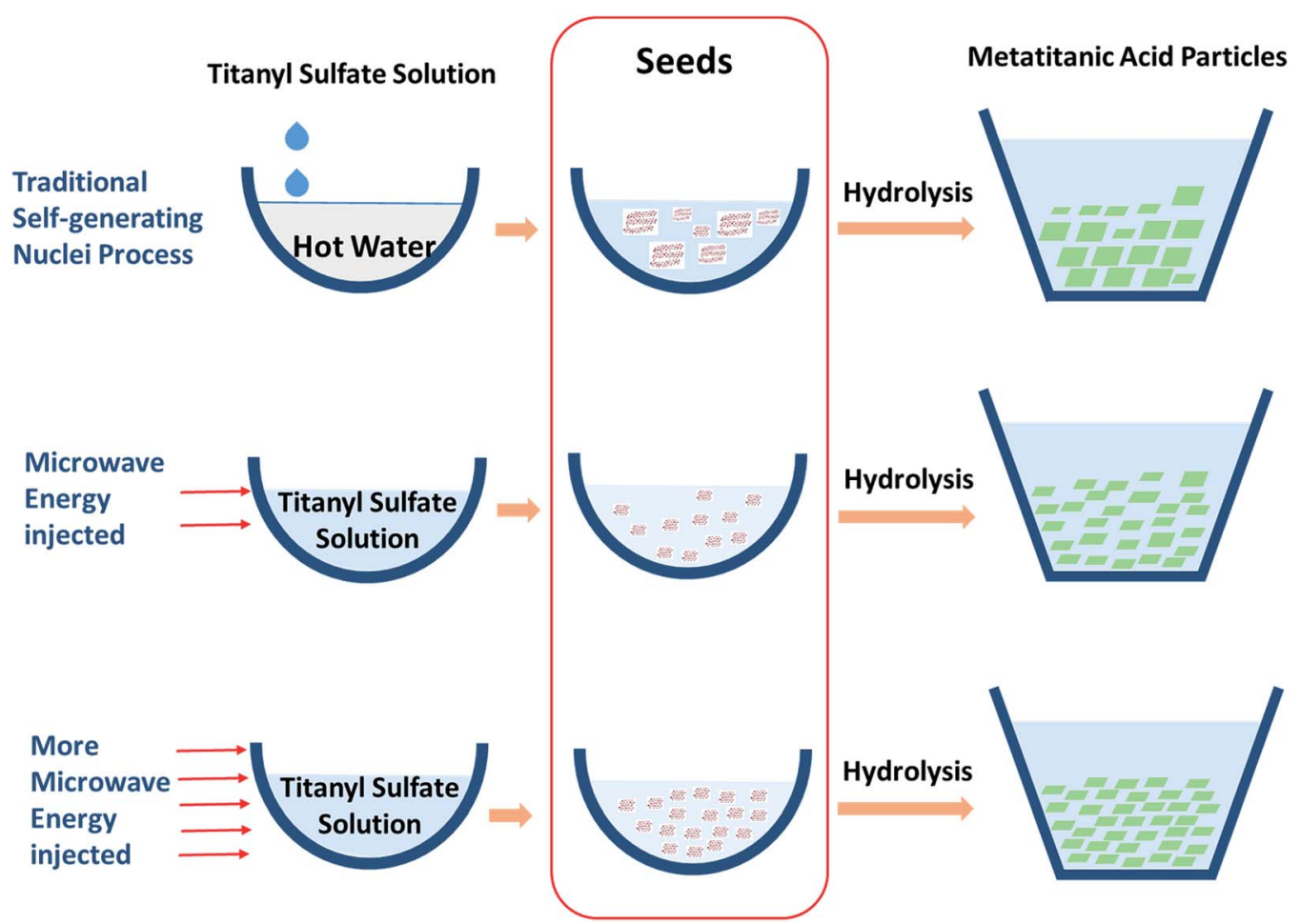

Fig. 4 Microwave heating effects on the seed preparation and the hydrolysis particle distributions.

ratios were over $90 \%$. With the $\mathrm{H}_{2} \mathrm{SO}_{4} / \mathrm{TiO}_{2}$ mass ratio increasing, the hydrolysis ratio dropped drastically. This tendency was similar to other $\mathrm{TiO}_{2}$ manufacturing processes. ${ }^{45,48}$ At a low concentration of hydrolysis liquid of titanyl sulfate solution, the stability of the solution was poor. Adding the iron ions in the solution could promote ion hydration, and leading to a higher stability of the hydrolysis, which would benefit the hydrolysis reaction. Therefore, to get titanium dioxide with good pigment properties, a certain ion concentration was necessary to ensure the growth of the grains on the crystallization center. ${ }^{49}$

Table 4 Effects of hydrolysis conditions ${ }^{a}$

\begin{tabular}{lllll}
\hline No. & $\begin{array}{l}\text { Seeds added amount } \\
\text { (mass ratio, \%) }\end{array}$ & ${\mathrm{Fe} / \mathrm{TiO}_{2}}$ & $\mathrm{H}_{2} \mathrm{SO}_{4} / \mathrm{TiO}_{2}$ & $\begin{array}{l}\text { Hydrolysis } \\
\text { ratio }(\%)\end{array}$ \\
\hline 1 & 2.0 & 0.0 & 1.9 & 94.4 \\
2 & 2.0 & 0.1 & 1.9 & 93.9 \\
3 & 2.0 & 0.2 & 1.9 & 94.4 \\
4 & 2.0 & 0.4 & 1.9 & 95.4 \\
5 & 2.0 & 0.3 & 2.0 & 94.3 \\
6 & 2.0 & 0.3 & 2.2 & 85.7 \\
7 & 2.0 & 0.3 & 2.4 & 63.2 \\
8 & 2.0 & 0.3 & 2.5 & 56.3 \\
9 & 2.5 & 0.3 & 1.9 & 95.1 \\
10 & 1.5 & 0.3 & 1.9 & 94.6 \\
11 & 1.0 & 0.3 & 1.9 & 92.1 \\
12 & 0.5 & 0.3 & 1.9 & 89.9
\end{tabular}

${ }^{a}$ The HTS concentration was $160 \mathrm{~g} \mathrm{~L}^{-1}$, the hydrolysis temperature was $104{ }^{\circ} \mathrm{C}$ and hydrolysis time was $3.5 \mathrm{~h}$. The seeds were prepared under STS concentration of $30 \mathrm{~g} \mathrm{~L}^{-1}$, the microwave heating power was $800 \mathrm{~W}$ and the microwave heating time was $60 \mathrm{~s}$.
A suitable $\mathrm{H}_{2} \mathrm{SO}_{4} / \mathrm{TiO}_{2}$ mass ratio can also increase the stability of the hydrolysis liquors. However, since sulfuric acid is the product in the hydrolysis reaction, too high a concentration of sulfuric acid would result in a strong restraining effect of the sulfuric acid in the hydrolysis reaction. And it would lead to a low hydrolysis ratio and a small particle size.

The metatitanic acids obtained with different $\mathrm{Fe} / \mathrm{TiO}_{2}$ mass ratios were characterized as shown in Fig. 5. Although the mass ratio of $\mathrm{Fe} / \mathrm{TiO}_{2}$ affected the hydrolysis ratio little, it did affect

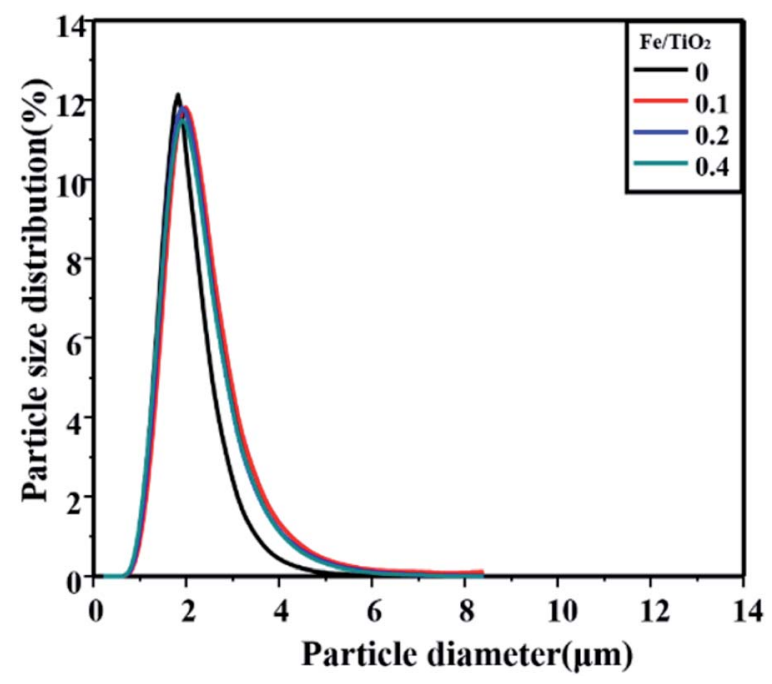

Fig. 5 Particle size distributions of hydrolysis products with different $\mathrm{Fe} / \mathrm{TiO}_{2}$ mass ratios. 


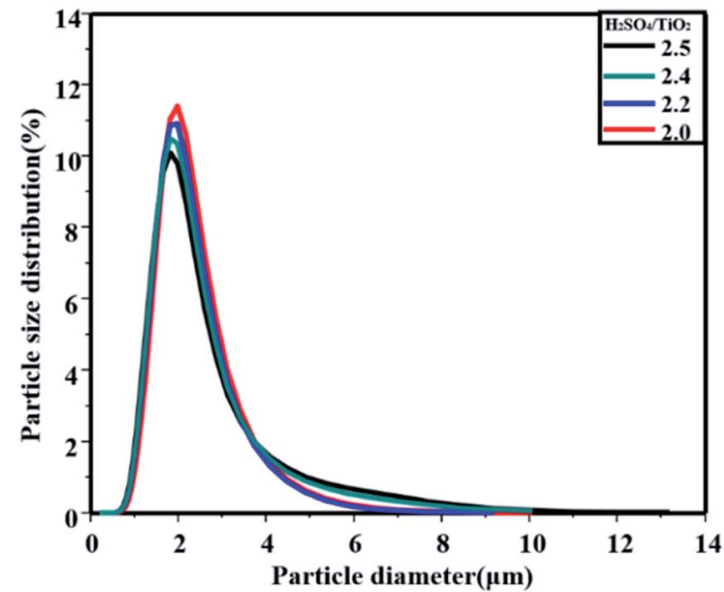

Fig. 6 Particle size distributions of hydrolysis products with different $\mathrm{H}_{2} \mathrm{SO}_{4} / \mathrm{TiO}_{2}$ mass ratios.

the particle size distribution of the products. When $\mathrm{Fe} / \mathrm{TiO}_{2}$ was 0 , the particle size distribution was narrower than the others. This may be caused by the iron ion concentration substantially affecting the morphology of metatitanic acid. ${ }^{47}$

As shown in Fig. 6, the particle size distribution of the products was obviously affected by the mass ratio of $\mathrm{H}_{2} \mathrm{SO}_{4}$ / $\mathrm{TiO}_{2}$. Since $\mathrm{H}_{2} \mathrm{SO}_{4}$ was the product of the hydrolysis process, the hydrolysis process was restrained with a high initial $\mathrm{H}_{2} \mathrm{SO}_{4}$ concentration, and the crystals grew with difficulty. As a consequence, the smaller crystals were easier to aggregate, finally causing the metatitanic acid particle size distribution to widen.

The hydrolysis particle changes along with the hydrolysis time are shown in Fig. 7. Overall, as the hydrolysis proceeds, the

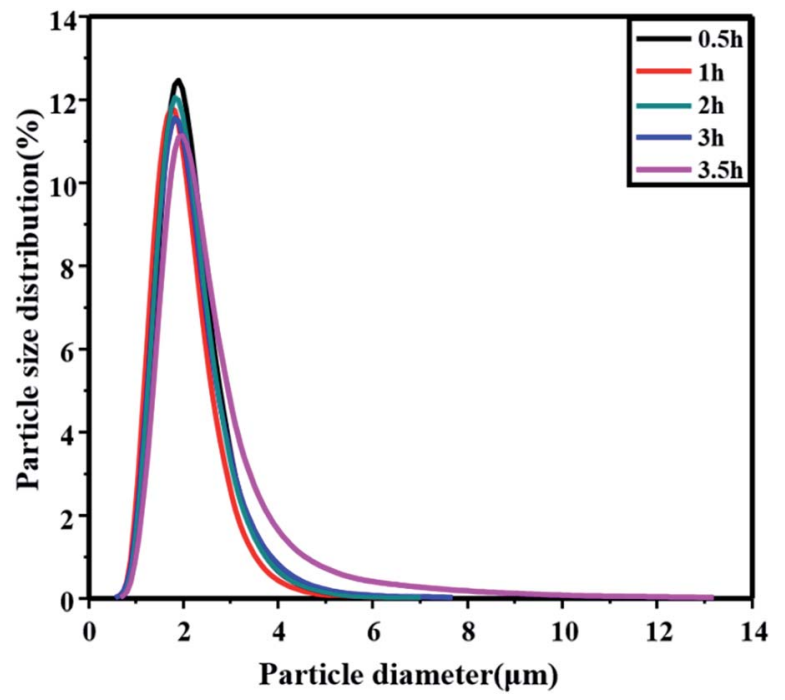

Fig. 7 The particle size distribution of metatitanic acid with different hydrolysis times. The experiments were carried out under the following conditions: STS concentration of $30 \mathrm{~g} \mathrm{~L}^{-1}$, microwave heating time of $40 \mathrm{~s}$, HTS concentration of $160 \mathrm{~g} \mathrm{~L}^{-1}, \mathrm{Fe} / \mathrm{TiO}_{2}$ mass ratio of $0.3, \mathrm{H}_{2} \mathrm{SO}_{4} / \mathrm{TiO}_{2}$ mass ratio of 1.9 , reaction temperature of $104^{\circ} \mathrm{C}$. particle size distribution of metatitanic acid widens obviously while the particle sizes were almost the same. The seeds added were the same in these entries. And the particle size distribution grew remarkably on the high diameter side, and the height of the peaks became less as the hydrolysis time increased from $0.5 \mathrm{~h}$ to $3.5 \mathrm{~h}$. At a hydrolysis time of $3.5 \mathrm{~h}$, the hydrolysis ratio was just about $67.3 \%$ (as shown in Table 1, No. 7), and the particle size distribution of metatitanic acid was similar to the results in Fig. 3. This suggested the final size distribution could be further widened and the particle size would tend to high particle diameters.

As discussed above, the particle size of metatitanic acid seemed to be relevant to the hydrolysis process, which means that the seeds added in the hydrolysis should be of a consistent particle size and activity. On the contrary, the particle size distribution of the metatitanic acid broadened with hydrolysis proceeding, because of the particles growing. This microwave-
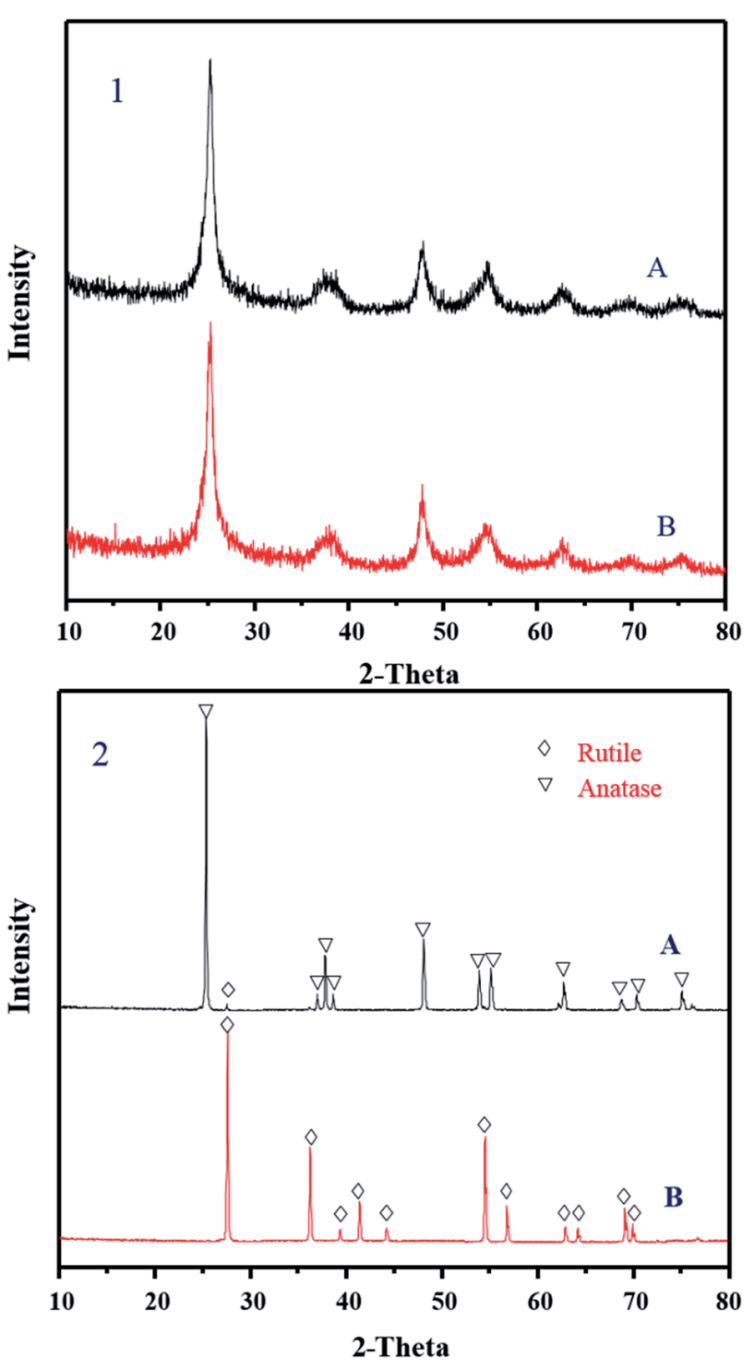

Fig. 8 XRD characterization for metatitanic acids produced by selfgenerating seeds and microwave-assisted seeds. (1A) Metatitanic acid produced by self-generating seeds. (1B) Metatitanic acid produced by microwave-assisted seeds. (2A) $\mathrm{TiO}_{2}$ produced by self-generating seeds. (2B) $\mathrm{TiO}_{2}$ produced by microwave-assisted seeds. 


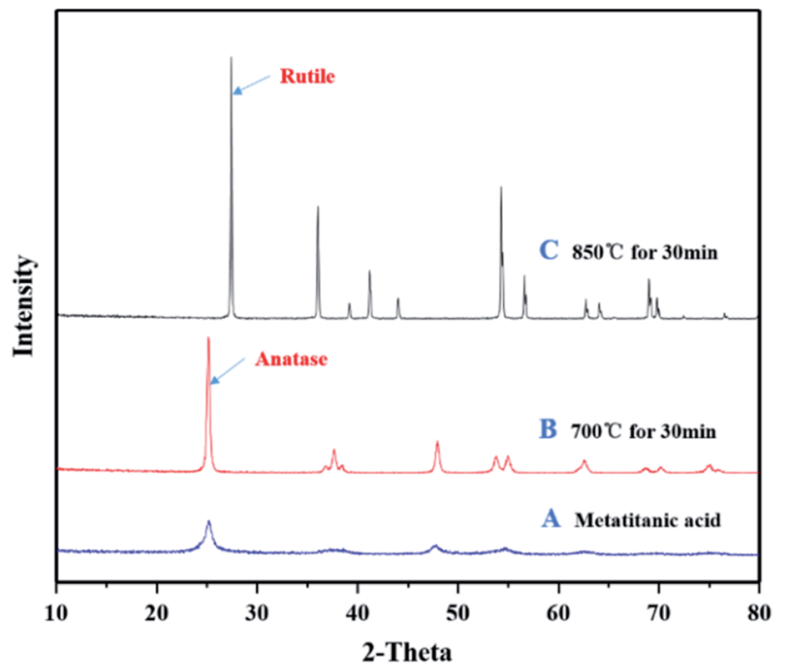

Fig. 9 XRD characterization of metatitanic acid calcined at different temperatures. (A) Metatitanic acid. (B) Calcination at $700{ }^{\circ} \mathrm{C}$ for $30 \mathrm{~min}$. (C) Calcination at $850^{\circ} \mathrm{C}$ for $30 \mathrm{~min}$.

assisted seed preparation method was proved to apply to different kinds of hydrolysis liquid. And a uniform product with a narrow particle size distribution could also be ensured with these seeds.

\subsection{Crystal transformation in calcination}

External crystal seeds decide the particle size and properties of the hydrolysis product, metatitanic acid. The pigment $\mathrm{TiO}_{2}$ is obtained by calcination of the hydrolysis metatitanic acid precursor, and the activity and properties significantly influence the pigment properties and also decide the crystal phases. $\mathrm{TiO}_{2}$ obtained from the hydrolysis precursor in the sulfate process is normally anatase-type $\mathrm{TiO}_{2}$. In order to produce rutile phase $\mathrm{TiO}_{2}$ pigment, the precursor is often subjected to an elevated temperature so that the crystal transforms from anatase to rutile in the presence of a crystal transforming agent. In this work, the crystal transformation in the calcination process was investigated for metatitanic acid obtained by the hydrolysis in the presence of external crystal seed.

In this section, the metatitanic acid produced under the conditions of seed concentration of $30 \mathrm{~g} \mathrm{~L}^{-1}$, mass ratio of $\mathrm{Fe} / \mathrm{TiO}_{2}$ of 0.3 , and $\mathrm{H}_{2} \mathrm{SO}_{4} / \mathrm{TiO}_{2}$ mass ratio of 1.9 was used to investigate the calcination process.

The hydrolysis samples obtained by using the microwaveassisted seeds as external crystal seeds were compared with the metatitanic acid products produced by self-generating seeds. XRD measurements showed that both metatitanic acid samples were anatase phase (as shown in Fig. 8, JCPDS 21-1272). Unlike commercial $\mathrm{TiO}_{2}$, the sample with microwaveassisted seeds converted to rutile (JCPDS 21-1276) after being calcined at $850^{\circ} \mathrm{C}$. While the product from the self-generating seeds process was mainly still anatase.

Fig. 9 demonstrates the XRD profiles of hydrolysis samples (microwave-assisted seeds) after undergoing calcination at different temperatures. The metatitanic acid products produced

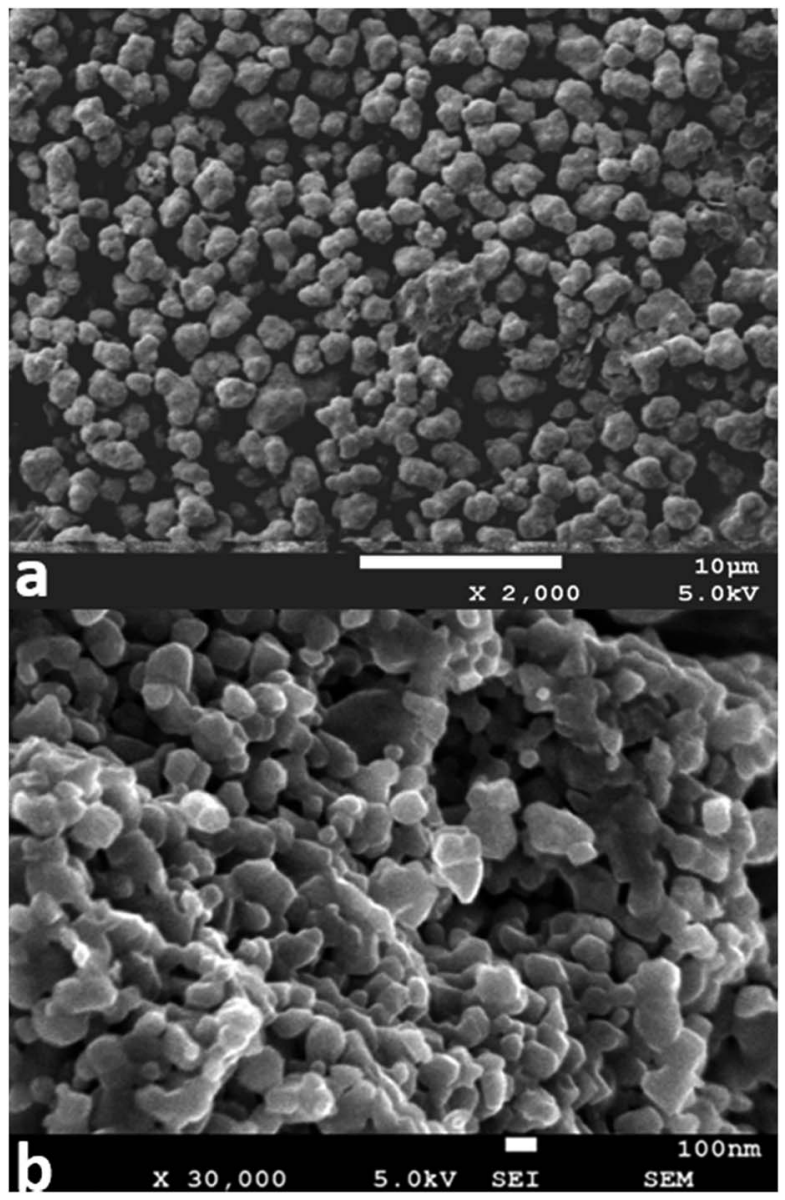

Fig. 10 Morphology of metatitanic acid particles and rutile particles by scanning electron microscopy. Seed concentration of $30 \mathrm{~g} \mathrm{~L}^{-1}$, $\mathrm{Fe} / \mathrm{TiO}_{2}$ mass ratio of $0.3, \mathrm{H}_{2} \mathrm{SO}_{4} / \mathrm{TiO}_{2}$ mass ratio of 1.9. (a) Metatitanic acid particles; (b) rutile products, with calcination at $850^{\circ} \mathrm{C}$ for $30 \mathrm{~min}$.

by microwave-assisted seed processes can easily transform to rutile crystal phase.

To further confirm the morphology before and after calcination, the metatitanic acid particles and rutile products produced with this microwave process were characterized using SEM, and the results are shown in Fig. 10. The metatitanic acid particles were approximately $1-2 \mu \mathrm{m}$ and of a narrow size distribution, which is consistent with the particle size analyzer results. The rutile particles are approximately uniform and of $100 \mathrm{~nm}$ in size, and could be considered to be uniform and small particles. This rutile particle size can be attributed to the narrow particle size distribution of metatitanic acid.

\section{Conclusions}

A novel microwave-assisted process to prepare seeds from dilute titanyl sulfate solution was developed for titanyl sulfate hydrolysis to produce anatase and rutile forms of $\mathrm{TiO}_{2}$.

Use of microwaves could lead to uniform seeds of small particle size. The seeds from this new process were proved to have an equal stability and activity. With microwave energy 
increasing, the activity of the seeds increased, while the stability decreased. This would lead to a higher hydrolysis ratio.

This microwave-assisted seed preparation technology was proved to be effective under different hydrolysis conditions. The particle size of metatitanic acid products was small (about 1-2 $\mu \mathrm{m})$, and the particle size distribution of the product was quite narrow and steady. The anatase product could easily transform to rutile (about $100 \mathrm{~nm}$ ) through calcination at an unexpectedly low temperature. Henceforth, the production of rutile from the sulfuric acid process prepared without crystal transfer seeds at low temperature could be realized.

\section{Conflicts of interest}

There are no conflicts to declare.

\section{Acknowledgements}

The authors are grateful for the financial support of the National Natural Science Foundation of China (NSFC 21236004).

\section{Notes and references}

1 Z. Chen and C. Liu, Manufacture and application of titanium dioxide pigments, Chemical Industry Press, 2006.

2 D. Antonelli and J. Ying, Angew. Chem., Int. Ed., 1995, 34, 2014-2027.

3 W. Zhang, Z. Zhu and C. Y. Cheng, Hydrometallurgy, 2011, 108, 177-188.

4 J. Zou, C. Yang and F. Peng, Rare Met. Mater. Eng., 2007, 4, 712.

5 W. Liu, Mod. Chlor-Alkali Technol., 2004, 8, 1-5.

6 X. Wu and S. Wu, Mod. Chlor-Alkali Technol., 1994, 5, 1-6.

7 W. Hixson and C. Ralphe, Ind. Eng. Chem., 1945, 37, 678-684.

8 H. Becker, E. Klein and H. Rechmann, Chem. Eng. J., 1964, 70, 779-787.

9 B. Grzmil, D. Grela and B. Kic, Pol. J. Chem. Technol., 2006, 8, 19-21.

10 C. Li, B. Liang and H. Wang, Hydrometallurgy, 2008, 91, 121129.

11 D. S. Chen, B. Song, L. n. Wang, T. Qi, Y. Wang and W. J. Wang, Miner. Eng., 2011, 24, 864-869.

12 S. Middlemas, Z. Z. Fang and P. Fan, Hydrometallurgy, 2013, 131, 107-113.

13 X. Xiong, Z. Wang, F. Wu, X. Li and H. Guo, Adv. Powder Technol., 2013, 24, 60-67.

14 B. Liang, C. Li, C. Zhang and Y. Zhang, Hydrometallurgy, 2005, 76, 173-179.

15 W. Zhang, C. Ou and Z. Yuan, Powder Technol., 2017, 315, 3136.

16 U. Barbara, D. Grela and B. Kic, Chem. Pap., 2008, 62, 18-25.

17 M. Monroe and E. Solomaka, Automated process for the hydrolysis of titanium sulfate solutions, US Pat., 3706829, 1972.

18 L. Piccolo, Process for the hydrolysis of titanium sulfate solutions, US Pat., 4014977, 1977.
19 D. Brisktown and R. Brian, Process for manufacturing titanium dioxide, US Pat., 4288418, 1981.

20 C. Tian, J. Du, X. Chen, W. Ma, Z. Luo, X. Cheng, H. Hu and D. Liu, Trans. Nonferrous Met. Soc. China, 2009, 19, 829-833.

21 J. Deng, Titanium pigment application manual, Chemical Industry Press, 2001.

22 B. Grzmil, M. Rabe, B. Kic and K. Lubkowski, Ind. Eng. Chem. Res., 2007, 46, 1018-1024.

23 Y. Wang, J. Li, L. Wang, T. Qi, D. Chen and W. Wang, Chem. Eng. Technol., 2011, 34, 905-913.

24 H. M. Wang, X. Tan and T. Yu, Appl. Surf. Sci., 2014, 321, 531537.

25 W. J. Zheng, X. D. Liu, Z. Y. Yan and L. J. Zhu, ACS Nano, 2009, 3, 115-122.

26 G. Zhao, W. Liu, S. Yang, L. Luo, J. Xu and G. Li, Chem. Eng. Commun., 2016, 203, 1207-1215.

27 S. Sekhar, D. Geoff and J. Micheal, Cryst. Growth Des., 2001, 2, 123-129.

28 J. Chen, W. Xu and J. Dai, Shandong Chem. Ind., 2012, 9, 1113.

29 Y. Liu, D. Shao, W. Wang, L. Yi, D. Chen, H. Zhao, J. Wu, T. Qi and C. Cao, RSC Adv., 2016, 6, 59541-59549.

30 M. Li, G. Xu, K. Xiong and Y. Ding, Chem. Ind. Eng. Prog., 2008, 27, 1056-1060.

31 S. Li, F. Xu, Y. Wang, S. Xu and L. He, Chin. Rare Earths, 2007, 28, 112-114.

32 J. Zhu and Y. Zhu, J. Phys. Chem. B, 2006, 17, 8593-8597.

33 H. Yang, C. Huang, A. Tang, X. Zhang and W. Yang, Mater. Res. Bull., 2005, 40, 1690-1695.

34 J. Park, J. Joo, S. Kwon, Y. Jang and T. Hyeon, Angew. Chem., Int. Ed., 2007, 46, 4630-4660.

35 M. Hu, C. Bai, S. Xu, G. Xu and D. Liang, Acta Phys.-Chim. Sin., 2008, 24, 2287-2292.

36 X. Wang, M. Han, Y. Wei and J. Wang, J. Synth. Cryst., 2004, 33, 634-637.

37 K. Sridhar, K. Rama and K. Hiroaki, Mater. Chem. Phys., 1999, 61, 50.

38 X. Quan and D. Li, Electron. Compon. Mater., 1998, 117, 38. 39 Y. Bykov and A. Eremeev, Nanostruct. Mater., 1999, 12, 115. 40 E. Vigil and L. Sadoun, J. Mater. Sci. Lett., 2001, 50, 295.

41 B. Xiang, Research on titanyl sulphate hydrolization kinetics, Chongqing University, 2001.

42 W. Luo, S. Yu and J. Ye, Paint Coat. Ind., 1999, 1, 19-20.

43 J. Zhou, W. Xiao, Y. Gu, H. Gu and L. Hu, J. Inorg. Mater., 1997, 3, 403-408.

44 D. Bavykin, E. Savinov and P. Smirniotis, React. Kinet. Catal. Lett., 2003, 1, 77-84.

45 B. Grzmil, D. Grela, B. Kic and M. Podsiadły, Pol. J. Chem. Technol., 2008, 10, 4-12.

46 W. Wang, Y. Liu, T. Xu, J. Li, D. Chen and T. Qi, Chem. Eng. Sci., 2015, 135, 196-204.

47 C. Tian, S. Huang and Y. Yang, Adv. Mater. Res., 2013, 602604, 1255-1260.

48 J. Jalava, Ind. Eng. Chem. Res., 1992, 31, 608-611.

49 L. Zheng, B. Liang, L. Lü, L. Jia and C. Li, Res. Chem. Intermed., 2015, 41, 5423-5438. 